\title{
An anomalous cluster of Irukandji jelly stings (Cnidaria: Cubozoa: Carybdeida) at Ningaloo Reef
}

\author{
Lisa-Ann Gershwin' and Peter Hannay ${ }^{2}$ \\ ${ }^{1}$ CSIRO Marine and Atmospheric Research, Castray Esplanade, Hobart, Tasmania 7000, Australia. \\ 2 District Medical Officer, Exmouth Hospital, PO Box 126, Exmouth, Western Australia 6707, Australia. \\ Email: lisa-ann.gershwin@csiro.au
}

KEYWORDS: Irukandji syndrome, envenomation, Western Australia, Indian Ocean, Carukia, Malo, Keesingia, Carukiidae

\section{INTRODUCTION}

An unusually large number of cases of Irukandji syndrome were reported in the northern regions of Ningaloo Marine Park (north of Coral Bay) and into Exmouth Gulf in the period March to June 2013. Seven confirmed sightings of three species of Irukandji jellies were also made during this event (Figure 1, Table 1). The purpose of this communication is to document this event and to provide preliminary information on the ecological context and medical implications.

Irukandji is the common name for numerous types of cubozoan jellies, and for the systemic illness caused by their stings (Williamson et al. 1996; Gershwin et al. 2013). The initial sting is typically mild, but after a delay of some 5-40 minutes, the syndrome onsets with a number of debilitating symptoms including severe lower back pain, nausea and vomiting, difficulty breathing, cramps and spasms, a feeling of impending doom; some cases also include life threatening hypertension.

Two species of Irukandji are currently known from Western Australia, both from the Broome region (Gershwin 2005). Seasonal clusters of stings have occurred in the Broome region for many decades, typically reported from inside Roebuck Bay through December each year, and then from the more exposed Cable Beach from February to June (Macrokanis et al. 2004; Gershwin et al. 2013).

The earliest cases of Irukandji syndrome reported in Australia were from Onslow in 1927 (Stenning 1928), long before the syndrome was named. Ningaloo Reef, however, typically has few or no sting reports each year. It was therefore unexpected when 23 people were hospitalised with Irukandji syndrome from this region in April-June 2013. A comprehensive study on the drivers and implications of high latitude stings is warranted to determine if this novel event is likely to recur.

\section{RESULTS AND DISCUSSION}

\section{Sting and specimen reports}

Twenty three reported hospitalisations due to Irukandji syndrome, along with three videos, three photographs, and one Irukandji specimen were recorded during this event (Table 1). Cases and sightings were reported from near Coral Bay, north into Ningaloo Marine Park and Exmouth Gulf.

Several additional less severe cases also occurred during this time. These had similar symptoms but did not require hospitalisation, while two more stings in August 2013 presented to the hospital in Coral Bay but did not require the standard magnesium treatment (unpublished data, Exmouth Hospital).

Near the height of this event in mid May, two drownings occurred together at Elle's Beach $50 \mathrm{~km}$ south of the southernmost reported stings; media highlighted that Irukandji could have been an underlying cause (AAP 2013). The coroner's report issued seven months after the event concluded that the deaths occurred by way of accident and that "there is no evidence to confirm or deny the involvement of Irukandji". Without nematocyst recovery from skin or observation of Irukandji-type symptoms prior to death, the involvement of Irukandji remains undetermined.

A swarm of what appear to be Irukandji jellies was observed at Rowley Shoals on the night of 9 September 2013 (Figure 2). Whether this swarm was in some way associated with the Ningaloo event is unknown.

\section{Species}

At least three genera of Irukandji were involved in this event, Carukia, Malo, and an unnamed genus and species in the family Carukiidae, determined by gross morphology observable in photos and videos. A single specimen was captured, and proved to be a new species 
of Malo. Both the Malo and the new carukiid have been described (Gershwin, 2014).

\section{Ecological context}

The ecological basis for this event has not yet been identified. Gelatinous zooplankton were prolific in 2013 (personal communication, Ben Fitzpatrick, dive tour operator with more than 15 years marine research experience at Ningaloo). In Queensland, the gelatinous pelagic community has been long associated with increased numbers of Irukandji, although the exact relationship has yet to be elucidated (Barnes 1964; Gershwin et al. 2013).

Climate conditions may prove informative. The summer months leading up to the bloom event were warmer overall than other years this century (Figure 3), and a substantial sea surface temperature (SST) spike occurred in February 2013 preceding the bloom event (Figure 4). These warmer conditions offer a number of hypotheses: an explosion in medusa production, a rapid increase in growth rate of already metamorphosed individuals, an increase over a threshold in toxin virulence, or a combination of the above. Photographic evidence (Table 1) and late summer activity suggest that Malo was the primary species; although the life cycle of Malo remains unknown, its size suggests that it is likely to be longer lived than Carukia (see Gershwin et al. 2013). Similarly, while nothing is known about the thermal ecology, growth rate, or toxin ontogeny of Malo, a reasonable beginning hypothesis is that it behaves like other medusae, i.e. that reproduction and growth are stimulated by an increase in temperature, and that virulence increases with growth (reviewed in Gershwin et al. 2013). Testing of these hypotheses is imperative.

Two other unusual high latitude clusters have occurred in Australia during or following heat waves: one at Fraser Island, Queensland in December 2012 and January 2013 (Walker 2013), and the other in Botany Bay, New South Wales in the 1930s (Cleland and Southcott 1965). The implications of this phenomenon in the context of planetary warming projections should be considered a high priority for further research.

Moreover, the majority of Ningaloo stings occurred in April and May in clusters coinciding with periods of southerly winds. Preliminary assessment of the environmental criteria established by CSIRO for forecasting Queensland Irukandji, indicate that favourable conditions coincided with the Ningaloo event (Gershwin et al. 2014). This suggests that with further study the occurrence of such events may become predictable.

\section{Medical notes}

Sting characteristics throughout the event fell into two fairly distinct categories: those with the 'normal' Irukandji presentation, and several with more severe life threatening symptoms (unpublished data, Exmouth Hospital). Of the more severe, two patients had near cardiac arrest, while a third had an anaphylaxis-like

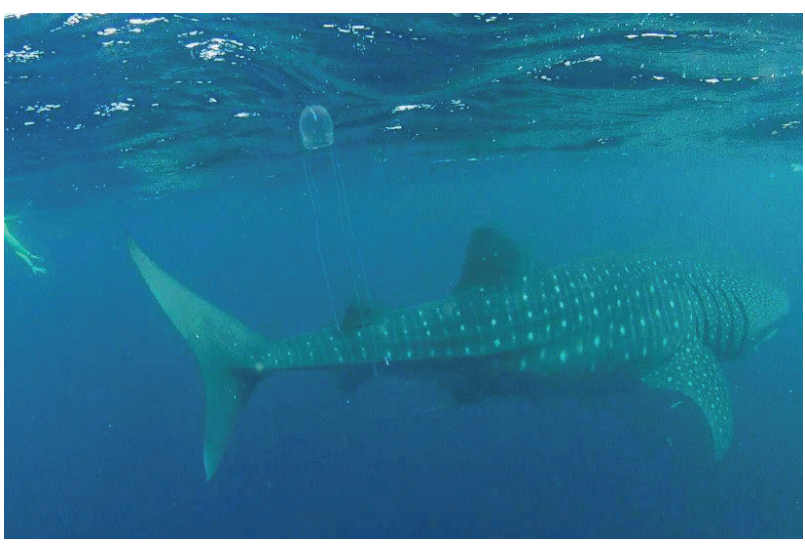

FIGURE 1 An Irukandji in the genus Malo at Ningaloo Reef, 13 July 2013; no stings were reported this day. This evidence of an Irukandji in the swimming area demonstrates the need for urgent research into prediction and management. (Image courtesy Ben Fitzpatrick / Oceanwise Expeditions.)

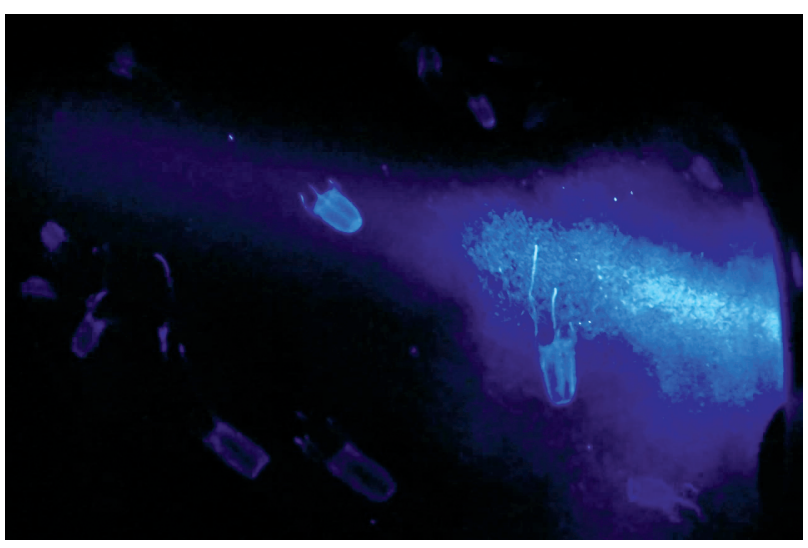

FIGURE 2 Swarm of carybdeid jellies approximately $10 \mathrm{~cm}$ long at Rowley Shoals on 9 September 2013. No specimens were collected so species identification could not be determined.

presentation. While Irukandji syndrome is often attributed to anaphylaxis in developing countries, the two responses are quite distinct. Anaphylaxis is an immune-mediated personal problem that causes difficulty breathing via mouth and/or throat swelling, while Irukandji syndrome is a public health problem that causes difficulty breathing via chest constriction or pain. However, the Ningaloo case was sufficiently convincing to cause the treating physician to run a diagnostic test for mast cell tryptase, which proved normal. An Irukandji sting in November 2012 also presented as anaphylaxis-like with a normal mast cell tryptase test; in this case, the pulse was 146 and the patient nearly arrested, but settled with administration of magnesium sulphate. The significance of the similarity of these 
TABLE 1 Irukandji stings and specimens from the vicinity of Ningaloo Reef in autumn and winter (April to July) 2013. Although a total of 23 hospitalisations were recorded, not all data could be accessed at the time of this report.

? indicates patient data not currently available.

\begin{tabular}{lll} 
Date & Patient & Notes \\
\hline First week of April & $\begin{array}{l}9 \text { stings requiring hospi- } \\
\text { talisation }\end{array}$ & Details unavailable; reported in media (ABC, 2013) \\
17 April & -- & Video of Carukia off Coral Bay (source unknown) \\
21 April & $?$ & On boat working out of Coral Bay, 70-80 km S of previous cases \\
27 April & -- & New species of Carukiidae photographed near Coral Bay (John Totterdell) \\
28 April & $17 \mathrm{yr} \mathrm{f}$ & Turquoise Bay, time 4 pm \\
10 May & $28 \mathrm{yr} \mathrm{m}$ & Anaphylactic-like reaction; mast-cell tryptase test negative \\
16 May & $19 \mathrm{yr} \mathrm{f}$ & \\
17 May & $53 \mathrm{yr} \mathrm{m}$ & \\
18 May & $46 \mathrm{yr} \mathrm{f}$ & \\
20 May & $14 \mathrm{yr} \mathrm{f}$ & \\
$21 / 22$ May & $54 \mathrm{yr} \mathrm{f}$ & 180/110 BP, hypertensive crisis, required two lots of Nifedipine \\
19 May & $?$ & \\
10 June & $45 \mathrm{yr} \mathrm{f}$ & Diver, back of reef \\
3 July & -- & 2 videos of Malo from Ningaloo Reef (source unknown) \\
13 July & -- & Malo photographed off Tantabiddi (Ben Fitzpatrick) \\
19 July & -- & New species of Malo collected by DPaW \\
\hline
\end{tabular}

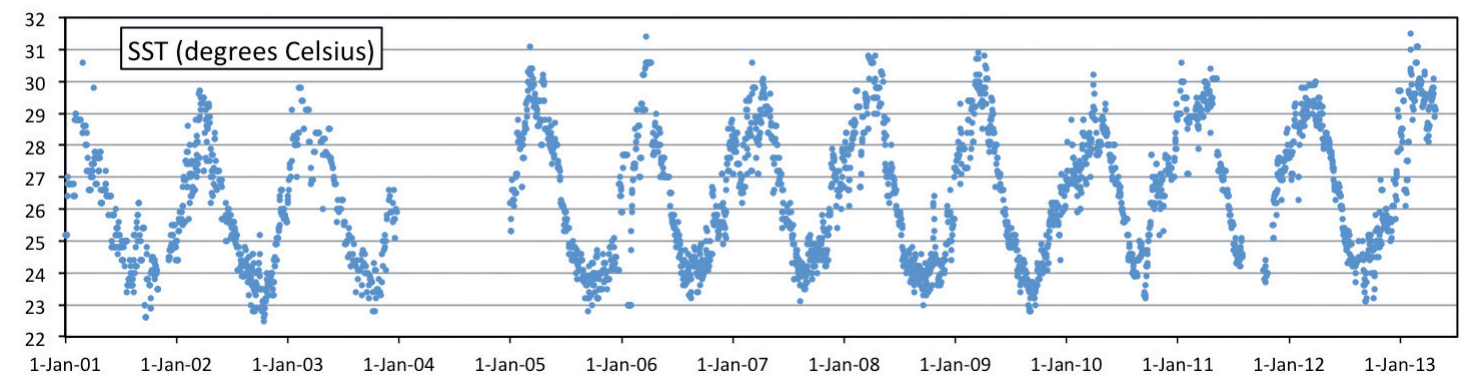

FIGURE 3 Daily sea surface temperature (SST) at the IMOS Ningaloo Reef mooring station, 2001-2013 (data for 2004 were not available at the time of this report). Horizontal axis increments correspond to 1 January of each year. Note the considerable temperature spike in early 2013 preceding the April to July Irukandji bloom event.

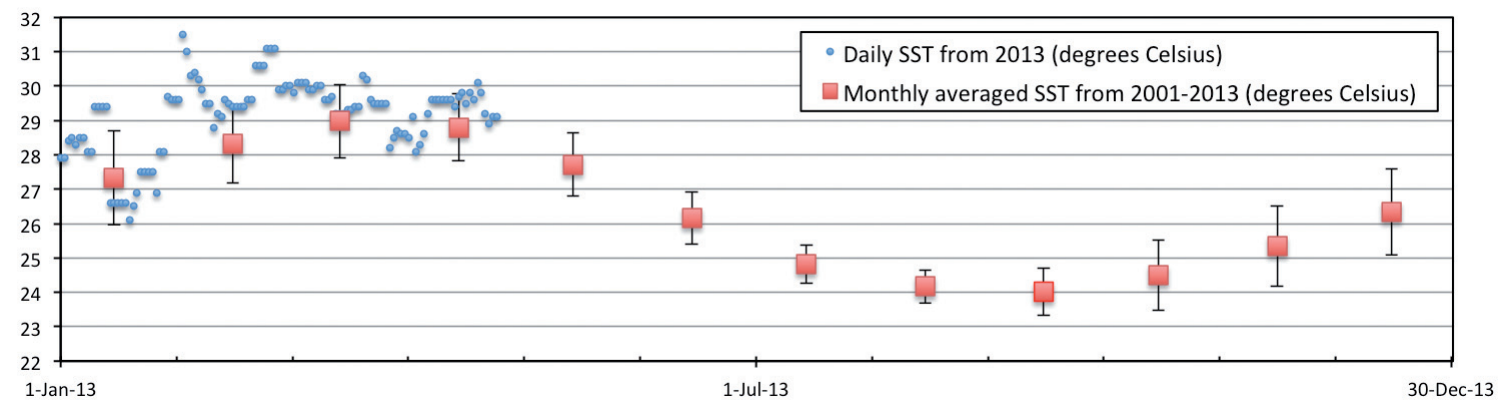

FIGURE 4 Ningaloo Reef mooring station long-term monthly average sea surface temperature (SST) $2001-2012$ (red squares), and daily SST for January to April 2013 (blue dots). Bars denote standard deviation. During February 2013 preceding the April to July Irukandji bloom event, the SSTs were more than 2 standard deviations above the mean, in the top $2 \%$ of SST values historically observed in this area (assuming that they follow a normal distribution). 
cases with anaphylaxis is not yet well understood.

The catecholamine excess of Irukandji syndrome may complicate Takotsubo Syndrome, also known as Stress Cardiomyopathy or Octopus Heart Syndrome, where exertion and subsequent adrenaline release in people over 50 years of age leads to a weakening of the left ventricle. This may be particularly relevant where vigorous swimming and excitement are combined where stings occur in recreational aquatic environments.

\section{Conclusion}

It is unclear why so many Irukandji were observed and yet relatively few stings occurred, compared with typical experiences in Queensland and overseas where the jellies are rarely observed.

The local, State, and national response to dealing with this event was challenged by the unexpected nature of it in this region. This raises the issue of planning in other regions that may consider themselves 'safe' from such visitations due to their southerly locations. A local alert system for dissemination of high risk conditions and safety information and a system of standardised data collection should be considered, along with establishment of forensic protocols to identify or rule out Irukandji as a cause of morbidity or mortality.

\section{ACKNOWLEDGMENTS}

We sincerely thank (in chronological order) Dr Peter Barnes from the Department of Parks and Wildlife, without whose assistance this report would not have been possible; Dr Roger Proctor of Australia's Integrated Marine Observing System (IMOS) for the temperature data; and Dr Scott Condie, CSIRO Marine and Atmospheric Research, for the splendid figures and discussions about the data patterns. We are also grateful for the many snippets of information, photos, videos, and other details from local residents, tourism operators, and tourists that assisted this report. We are also grateful for the helpful comments from Dr John Keesing and an anonymous referee; the paper was much improved as a consequence.

\section{REFERENCES}

AAP. (2013). Tragedy: Deadly jellyfish theory in Ningaloo deaths. West Australian. http://www.perthnow.com.au/ news/western-australia/canberra-man-still-missing-fourdays-after-his-wife-died-snorkelling-off-coral-bay/storyfnhocxo3-1226646195828. Accessed 11 March 2014.

ABC. (2013). Spate of toxic jellyfish stings off north west. ABC News Online. http://www.abc.net.au/news/201304-11/spate-of-toxic-jellyfish-stings-of-north-westcoast/4623972?section=wa. Accessed 11 March 2014.

Barnes, J.H. (1964). Cause and effect in Irukandji stingings. Medical Journal of Australia 1(24): 897-904.

Cleland, J. B. and R. V. Southcott. 1965. Injuries to Man from Marine Invertebrates in the Australian Region. Commonwealth of Australia: Canberra.

Gershwin, L., Condie, S.A., Mansbridge, J.V., and Richardson A.J. (2014). Dangerous jellyfish blooms are predictable. Journal of the Royal Society Interface 11: $20131168 \mathrm{http}: / /$ dx.doi.org/10.1098/rsif2013.1168.

Gershwin, L., Richardson, A.J., Winkel, K.D., Fenner, P.J., Lippmann, J., Hore, R., Avila-Soria, G., Brewer, D., Kloser, R., Steven, A. and Condie, S. (2013). Biology and ecology of Irukandji jellyfish (Cnidaria: Cubozoa). Advances in Marine Biology 66: 1-85.

Gershwin, L. (2005). Two new species of jellyfishes (Cnidaria: Cubozoa: Carybdeida) from tropical Western Australia, presumed to cause Irukandji Syndrome. Zootaxa 1084: $1-30$.

Gershwin, L. (2014). Two new species of box jellies (Cnidaria: Cubozoa: Carybdeida) from the central coast of Western Australia, both presumed to cause Irukandji Syndrome. Records of the Western Australian Museum 29(1): 10-19.

Macrokanis, C.J., Hall, N.L. and Mein, J.K. (2004). Irukandji syndrome in northern Western Australia: an emerging health problem. Medical Journal of Australia 181(11/12): 699-702.

Stenning, A. E. (1928). Poisoning by Trachymedusae. Medical Journal of Australia 1(May 5): 568-569.

Walker, J. 2013. Stinger strikes seventh time. The Australian, 8 January. Canberra. p.3.

Williamson, J. A., P. J. Fenner, J. W. Burnett and J. Rifkin, Eds. 1996. Venomous and Poisonous Marine Animals: A Medical and Biological Handbook. NSW University Press: Sydney.

MANUSCRIPT RECEIVED 11 NOVEMBER 2013; ACCEPTED 6 APRIL 2014. 